\section{ECONOMICS}

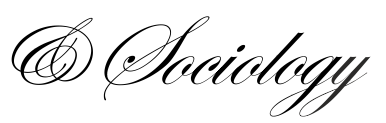

\title{
JOB SATISFACTION AND SUBJECTIVE WELL-BEING IN EUROPE
}

\author{
Massimo Cannas, \\ University of Cagliari, Italy \\ E-mail:massimo.cannas@unica.it \\ Bruno S. Sergi, \\ Harvard University, USA \\ \& University of Messina, Italy \\ E-mail:bsergi@fas.barvard.edu \\ Emiliano Sironi, \\ Università Cattolica del Sacro \\ Cuore, Italy \\ E-mail:emiliano.sironi@unicatt.it \\ Urszula Mentel, \\ Rzeszón University of Technology, \\ Poland \\ E-mail:u.mentel@prz.edu.pl
}

Received: August, 2019

1st Revision: August, 2019

Accepted: October, 2019

DOI: $10.14254 / 2071-$

789X.2019/12-4/11

JEL Classification: J28, I31

\begin{abstract}
This paper addresses some recent developments in the field of management science and economics of well-being, trying to prove a link between working conditions and subjective well-being. Using the fifth round of the European Social Survey, which is the most recent set of data with a module focusing on the inter-relations between work, family and well-being, this paper uses an instrumental variable approach to estimate the effect of job satisfaction on subjective Well-being. The direction of the relationship between these two variables has always been controversial because of endogeneity. Results, also exploring the role of working contract and welfare systems, allow for isolating a considerable influence on job satisfaction in increasing people's subjective well-being. Results are robust even if the restriction condition is violated. Job satisfaction increases subjective well-being even if the instrumental variables are not uncorrelated with the error of the main equation.
\end{abstract}

Keywords: job satisfaction, subjective wellbeing, management, instrumental variables, validity of the instruments, European Social Survey.

\section{Introduction}

The concepts of Subjective Wellbeing (SWB), Happiness and Quality of Life have become central in contemporary scientific debate. If a great stem of literature investigated differences in the abovementioned constructs for defining SWB (Medevedev \& Landhuis, 2018), another stem of scientific debate was focused on the determinants of wellbeing. In this sense, the role of employment has been recognized to be fundamental in explaining wellbeing (Sironi, 2019) in multiple dimensions. This paper is concerned with the relationship between job satisfaction (JS) and subjective wellbeing (SWB). This is particularly interesting because of job satisfaction and wellbeing at the workplace increase employees' performance (Luthans 
et al. 2007; Bakotic, 2016). While it is well-known that these two concepts are somehow related, the direction of causality is debated in literature. As suggested by Judge and Locke (1993), Judge et al. (1998), Locke (1976), Near et al. (1978), Rice et al. (1980), Sironi (2019), job satisfaction could be viewed as a sub-dimension of SWB. This first approach refers to the "partwhole" theory or "spillover" hypothesis. The second stem of scientific debate (known as "dispositional approach") conceives SWB as a general predisposition of the individual to transfer overall satisfaction towards specific life domains, such as in the works of Diener (1984), Headey et al. (1991), Judge and Hulin (1993) and Judge and Watanabe (1993). Under the first approach, one would expect a relationship that runs from job satisfaction to SWB; and under the second approach, one would expect to observe a reverse relationship, running from SWB to job satisfaction. In this analysis, without denying that overall SWB may reflect on satisfaction in a specific life domain like job satisfaction, this paper supports the first approach trying to estimate the impact of job satisfaction on SWB with more robust methods than those presented in the literature to date.

Earlier studies have tried to address the problem of reverse causality using longitudinal analyses (Bowling et al., 2010). More recent ones (Sironi, 2019) implemented instrumental variable approaches in a cross-sectional setting with the advantage of using an innovative and composite measure of wellbeing (Optimal Wellbeing as in Huppert and So, 2013), with the restriction of using a binary wellbeing indicator instead of a metrical outcome variable and with the limit of using commonly accepted but criticized tests for supporting the choice of instrumental variables (Clarke and Matta, 2018). Hence, in the past study, validity of restriction conditions is only partially investigated. This paper uses cross-sectional data from the fifth round of the European Social Survey (ESS), which included a unique questionnaire with the detailed information on both SWB and job satisfaction, taking into account also the geographical origin of the respondents. Because of the cross-sectional nature of data in this paper, a different method for disentangling the interplay between SWB and job satisfaction was used, by implementing an instrumental variable (IV) approach. Traditional tests and innovative robustness checks are implemented in order to support the IV estimation procedure.

The remainder of the paper is structured as follows: section 1 reviews the existing literature on the relationship between SWB and job satisfaction; section 2.1 and section 2.2 respectively describe data and methods used in the empirical analysis with the description of the set of explanatory variables (in paragraph 2.3), while section 3 reports the estimation results. Concluding remarks follow in section 4 .

\section{Literature review}

Because of the special focus of this paper on the interplay between SWB and job satisfaction (JS), the literature review is devoted to summarizing the most relevant results and studies concerning both dimensions of interest.

The concept of SWB is linked to the concept of happiness, which in turn is connected to the concept of Eudaimonia, first developed by philosophers in ancient Greece. This connection has been confirmed by Bruni (2010) and Diener (1984), one of the pioneers in the research on SWB, reporting that "although human unhappiness was analyzed in depth [...] little theoretical progress in understanding happiness has been made in the two millennia since the time of the Greek philosophers".

Given the long tradition at the base of the concepts of happiness and SWB, recent economic research deeply focused on them, addressing the link between individual determinants and SWB. Indeed, as pointed out by Frey and Stutzer (2002), there are not many goals in life, other than being happy, that are shared by so many people. 
However, happiness is a complex concept and the lack of a universally accepted definition makes it a difficult topic to be defined. To try to overcome these difficulties, it is to be underlined that, even though the terms "subjective well-being", "happiness" and "life satisfaction" have often been used interchangeably, psychological literature distinguishes them: in general, "happiness" and "life satisfaction" are classified as components of SWB (Diener et al., 2002): "happiness" is the result of a balance between positive and negative affect, whereas "life satisfaction" expresses the perceived distance of realized quality life from individuals" aspirations (Bruni and Porta, 2007). In more detail, the term happiness is used to refer to the affective element of SWB, or the presence of pleasant emotions and absence of unpleasant emotions, while life satisfaction represents the cognitive element.

Frey and Stutzer (2002) summarize the determinants of happiness into three sets of predictors: economic (generally unemployment, income and inflation), socio-demographic (age, gender, health, etc.) and institutional (the type of democracy, the level of government decentralization, etc.). In general, evidence has shown that levels of happiness and life satisfaction, when combined, shape the concept of SWB and are rather stable over time (Diener, 2000; Lucas et al., 2003; Suh et al., 1996).

Defining the role of happiness and life satisfaction and their determinants allows us to address the link between well-being and a specific domain. Work has always been considered a pivotal aspect of life (Yahyagil, 2015): on one hand in standard microeconomic models addressing the trade-off between leisure and time spent to work, an increase in the hours dedicated to leisure (and consequently a decrease in those dedicated to work) would have enhanced the individual's utility, ceteris paribus. On the other hand, empirical research on happiness clearly showed that being unemployed, even when receiving the same income as when employed, induces a decline in people's well-being (Frey and Stutzer, 2002). It turns out that unemployment status reduces well-being more than any other single factor, even in comparison to crucial and depressive life course events as widowhood, divorce and separation as pointed out by Clark and Oswald (1994). This supports the implementation of welfare policies more oriented to help people with lower levels of income improving the quality of their job, than providing them monetary compensation.

The effect of job satisfaction on subjective well-being can be not just direct one, there is a lot of intermediaries, like gender or religious perception of the life quality (Bilan et al., 2019), attitude to the trust (Lazányi \& Bilan, 2017), the hours worked vs salaries earned in teh contest of the intertemporal labour substitution (Šabić-Lipovača etc, 2016), organizational culture and organizational culture dimensions (Stefanovska-Petkovska etc, 2019), the managing or non-managing position (Stefanovska-Petkovska et al., 2019; Bratu \& Cioca, 2018).

Thus, by means of the sound regression analyses it was detected that negative perceptions regarding standard of living cause religiosity, but also allows for more satisfaction in daily life (Bilan et al., 2019). Such an evidence was claimed for the economically developing countries, particularly Turkey, Ukraine, Senegal, and Morocco, however, it is still relevant to other developing economies of Eastern Europe, North Africa, and the Middle East.

As to the aspect of trust, it is in its turn relevant to the generation origin, culture origin and, thus, varies in years and over the world (Lazányi \& Bilan, 2017). And if before the values were mostly similar in the world - like respect to the experience that came with age, now it turned to opposite. The results of the indicated authors reflected that respect and trust towards superiors are not automatic as it is supposed to be earned through professional excellence. In our thoughts, the attitude of the adult colleagues on the job satisfaction and its components as well as the factors and markers of well-being has been changed for the new generations. The same is about the pushers of job satisfaction: financial versus non-financial. It appears that 
financial incentives tend to be stronger predictors for the older workers (Stefanovska-Petkovska \& Bojadziev, 2017).

That, received the one more evidence in the study of D'Silva \& Samah (2018), who found out that the holistic well-being of retirees in the host country is $56.3 \%$. Meanwhile, the dimensions of communication technologies and lifestyle were scored the highest. On the other hand, the lowest scores got the dimensions of political and physical facilities. It was the case of Japanese retirees in Malaysia, but it is mirrowed over the world.

The job satisfaction as well is not constant value for different fields of activity. Thus, for the teachers it could be one number of triggers (like salary, promotion, benefits, coworkers, type of work done, and communication within the organization) but for the marketing managers it could be frontally different. Hameed etc (2018) revealed statistically significant differences in degree of job satisfaction even between the Public and Private University Teachers.

Recently, the pillar of the topic has changed from the job satisfaction to the opposite side of the coin - job burnout. There are some studies that on the base of the regression models provide evidence that job stress, job involvement, job satisfaction, affective commitment, and continuance commitment have great effects on burnout (Lambert et al., 2018). That produces new discourse on how leadership and reducing job stress and continuance commitment and increasing job involvement can affect job satisfaction and affective commitment among officers (Boamah et al., 2018).

In our paper, we use a double-item approach to build a suitable measure of SWB, combining the answers of two items measuring life satisfaction and happiness.

Similarly to what concerns the construct of SWB, the concept of job satisfaction (JS) is also ambiguous and several definitions can be formulated. To summarize, JS can be defined as the degree of contentment a person feels regarding his job and the sense of accomplishment he gets from doing it. It can be classified into two different dimensions: affective and cognitive satisfaction. Affective satisfaction refers to a person's emotional feeling about the job as a whole, whereas cognitive satisfaction reflects how satisfied employees feel concerning some aspects of the job.

The basics of JS lie in the fact that we are rewarded for the job we do. This reward can take different forms: it can be monetary or mostly intangible, for instance, the feeling one gets from jobs that help others or the prestige that comes from performing a specific job. Rewards can also rely on the chances to advance in career.

However, not all aspects of job satisfaction are reward-related. Some of the most important factors affecting job satisfaction deal with the working conditions and workers' future perspectives (Poggi, 2010, Goyal et al. 2014). This approach underlines the importance of aspects like the total compensation (Igalens et al., 1999), the responsibilities incorporated in the job and opportunities to use workers' skills (Bryson et al., 2017). Also, promotion opportunities, the relationship with the supervisor and/or with coworkers and job security (Baptiste, 2008; Foote and Li-Ping Tang, 2008, Bryson et al., 2007) are remarkable elements that augment JS. Other aspects that are classified as important are the contribution of an employee to the organizational business goals, the overall corporate culture and the organizational commitment to corporate social responsibility.

One approach that is widely used for classifying all these factors is Herzberg's twofactor theory (1976). The basic idea is that there are certain factors in the workplace, causing satisfaction and others causing dissatisfaction. In his conceptualization, the factors that promote positive satisfaction are called motivators: elements such as achievement, recognition, the work itself and responsibility belong to this category. The so-called hygiene factors, instead, do not directly provide employees with positive satisfaction, though dissatisfaction results from their 
absence; these are extrinsic from work itself. Some examples include job security, work conditions, company policies, supervisory practices, salary, etc.

Differently from the case of SWB, in this paper, JS is measured through a single-item scale. This kind of measure has been subject to criticism if compared to multi-item scales. Although single-item scales are suspected of offering worse performance in terms of reliability, recent studies do not discard them with respect to JS (Dolbier et al., 2005).

\section{Methodological approach}

\subsection{Data}

The analysis has drawn from data collected in the fifth round of the ESS (2010). The ESS is an academically driven cross-national survey which has been a leader in monitoring social change in Europe since 2002. It has since then issued a multidimensional questionnaire across several European countries every two years. In the fifth round, there were 27 countries surveyed: Belgium, Bulgaria, Croatia, Cyprus, Czech Republic, Denmark, Estonia, Finland, France, Germany, Greece, Hungary, Ireland, Israel, Lithuania, Netherlands, Norway, Poland, Portugal, Russian Federation, Slovakia, Slovenia, Spain, Sweden, Switzerland, Ukraine, and the United Kingdom. Round five has been selected since it includes sections on work and family wellbeing with a specific module focused on SWB: the set of available information refers not only to SWB but also to the degree of satisfaction on specific aspects of the job.

\subsection{Methods}

The aim of this paper is to estimate the impact of job satisfaction on individual SWB, since this paper assumes that the former is one of the determinants of the latter. The model used in the analysis follows the approach of Sironi (2019) and is specified as follows:

$$
\mathrm{Y}_{\mathrm{i}}=\beta_{0}+\beta_{1} \mathrm{X}_{\mathrm{i}}+\beta_{2} \mathrm{~W}_{\mathrm{i}}+\varepsilon_{\mathrm{i}}
$$

Where $\mathrm{Y}_{\mathrm{i}}$ is the dependent variable, representing a measure of SWB for the individual $i . \mathrm{X}_{\mathrm{i}}$ is the main explanatory variable, which is a measure of job satisfaction for the individual $i$; $\mathrm{W}_{\mathrm{i}}$ is a set of control variables which consist of all the other exogenous regressors which are assumed to impact on SWB, according to the literature. Finally, $\varepsilon_{\mathrm{i}}$ represents the error. Since job satisfaction is potentially correlated with the error term, this paper argues that an IV regression would lead to a more reliable estimate than a standard ordinary least squares (OLS) regression (Schmalbach and Avila, 2018). Using an IV estimation means implementing an auxiliary regression where $\mathrm{X}_{\mathrm{i}}$ is a function of the exogenous control variables $\mathrm{W}_{\mathrm{i}}$ and of a set of predictors collected in the vector $Z_{i}$ that have the requirement of not being correlated with the error component of the main equation. The auxiliary equation has been defined in the following way:

$$
\mathrm{X}_{\mathrm{i}}=\alpha_{0}+\alpha_{1} \mathrm{Z}_{\mathrm{i}}+\alpha_{2} \mathrm{~W}_{\mathrm{i}}+\mathrm{u}_{\mathrm{i}}
$$

where $Z_{i}$ is the vector of instrumental variables not correlated with the error term of the first equation. After estimating $\left[\alpha_{0}, \alpha_{1}, \alpha_{2}\right]$ using equation (2), the prediction of $\mathrm{X}_{\mathrm{i}}$ obtained in (2) replaces $X_{i}$ in equation (1), giving robust estimates of the coefficient $\beta_{1}$. 


\subsection{Variables}

The dependent variable of the main equation is SWB, which has been obtained by computing the mean between two items measuring happiness and life satisfaction, respectively, as suggested by the literature review. The following two items were included in the questionnaire of the fifth round of ESS:

- " "Taking all things together, how happy would you say you are?"

- " "All things considered, how satisfied are you with your life as a whole nowadays?"

In both cases, low scores reflect unhappiness/dissatisfaction, while high scores are associated with high levels of happiness/satisfaction. The mean of the variable created was 6.81 , on a scale ranging from 0 to 10 . A summary of the other descriptive statistics about both items in the survey and the one generated for this paper are displayed in Table 1.

Table 1. Instrumental variable estimation diagnostic

\begin{tabular}{lc}
\hline Indicators & Mean (From 1 to 10) \\
\hline $\begin{array}{l}\text { Happiness indicator [A] } \\
\text { Taking all things together, how happy would you say you are? }\end{array}$ & $6.99 / 10$ \\
\hline $\begin{array}{l}\text { Life Satisfaction indicator }[B] \\
\text { All things considered, how satisfied are you with your life as a } \\
\text { whole nowadays?" }\end{array}$ & $6.63 / 10$ \\
\hline $\begin{array}{l}\text { SWB indicator } \\
\text { Mean of [A] and [B] }\end{array}$ & $6.81 / 10$ \\
\hline Observations & 51,993 \\
\hline
\end{tabular}

Notes: *** significant at 0.01 level, $* * 0.05$ level, $* 0.10$ level.

Source: ESS 2010

Job satisfaction is the main independent variable that is assumed to be endogenous. It also represents the dependent variable for the auxiliary regression and its predicted value (as a function of the instruments) has been included in the main model. The main problem concerns the identification of the set of the excluded variables that are considered to affect job satisfaction but not directly SWB. The literature helps to select the correct variables in order to determine job satisfaction: Frone et al. (1994) addressed the relationship between job satisfaction and family satisfaction, using job involvement, job stressors and family-work conflict as measures for job satisfaction. Saridakis et al. (2009) tried to reduce the bias in estimating the relationship between employee commitment and job satisfaction after implementing an instrumental variable approach in which job satisfaction depends on the quality of the job contract, trade union membership and the number of working hours, considered as a proxy for job suitability and a proxy for flexible working arrangements. Even if the context of the analysis is different from what we have considered in the present survey, Saridakis et al. (2009) provided evidence that the number of working hours may affect job satisfaction. Accordingly, this paper uses two items, assuming that the level of contentment with one's own job may be obtained with the answers to the questions:

- "How often does your work involve working at weekends?"; the possible responses were on an ordinal scale: "Never, less than once a month, once a month, several times a month, every week." 
- "How often does your work involve having to work overtime on short notice?": the possible answers were: "Never, less than once a month, once a month, several times a month, once a week, several times a week, every day."

Because both the variables are categorical and expressed on different scales, they were dummy coded: the value of one indicated a worker must work on the weekend or has to work overtime on short notice more than once a month and zero otherwise. Hence, a negative sign of the coefficient is expected for job satisfaction if working on the weekends or overtime are associated with lower job satisfaction.

The set of exogenous explanatory variables is listed below:

Income: following the evidence of a link between income and SWB (Diener et al., 1993), income has been introduced in the model; the questionnaire included ten ranges of income (deciles) available for the subjects surveyed. In order to simplify the analysis, the data are classified in quintiles. The first quintile, including the individuals with the lowest $20 \%$, was used as the reference category.

Marital status: six categories are created; legally married, in a legally registered civil union, legally separated, divorced/civil union dissolved, widowed, none of these (never married or in a legally registered civil union).

Gender: the variables take two possible values: one if the respondents are "Females" and zero if he is a "Male".

Age: because of the well documented U-shaped relationship with SWB (Blanchflower and Oswald, 2007), we introduced age in a quadratic form.

Foreigners: foreigners report significantly lower levels of well-being than nationals, according to the literature. Therefore, this dummy variable was added as another explanatory variable, with a value of one whenever the answer to the question "Were you born in [country where the survey is taking place]?" was "No" and assuming a value of zero otherwise.

Employment status: five different categories of workers were generated: fixed-term employee, permanent employee, employees with no contract, working for a family business and self-employed.

Education: summarized in a set of four dummy variables reflecting the International Standard Classification of Education (ISCED) developed by UNESCO in order to facilitate comparisons of education statistics and indicators across countries:

(i) Primary: a value of one indicated if the individual only completed basic or primary education (corresponding to ISCED level 0 or 1), and zero otherwise;

(ii) Lower secondary: a value of one indicated that the subject completed lower intermediate education, which is linked to ISCED level 2;

(iii) Upper secondary: a value of one indicated the individual completed either level 3 or 4 of the ISCED, that is an upper intermediate level of education corresponding to a high school diploma;

(iv) Tertiary: a value of one indicated that an individual completed at least ICED level 5, which corresponds to higher education: bachelor, master or Ph.D. diploma.

Welfare system: finally, this paper included in the regression the type of welfare system a country offers (Esping-Andersen, 1990; Soede et al., 2004) in order to allow for macroeconomic heterogeneity in determining well-being and job productiviy (Asatiani and Verulava, 2017; Kaasa, 2016). Hence, five macro-categories of welfare states exist in Europe: Nordic (grouping Denmark, Finland, Norway, Sweden and the Netherlands); Continental (Belgium, France, Germany and Switzerland); Anglo-Saxon (UK and Ireland); Mediterranean (Spain, Portugal, Cyprus and Greece); Eastern (Estonia, Lithuania, Bulgaria, Russian Federation, Slovakia, Ukraine and Croatia). A category named "Other" is included, to include a few 
countries, such as Israel, Slovenia, Czech Republic, Poland and Hungary, which can be classified in any of the earlier categories. Eastern is chosen as the reference category.

\section{Empirical results}

Table 2 displays the results of the empirical analysis. The table also compares the results obtained through the IV estimation, or two stage-least squares (2SLS), with those of an OLS regression.

Table 2. Regression Results: OLS and IV Estimations for the Determinants of Subjective wellbeing

\begin{tabular}{|c|c|c|c|}
\hline & \multicolumn{2}{|c|}{ 2SLS } & \multirow{2}{*}{$\begin{array}{c}\text { OLS } \\
\text { Subjective well-being }\end{array}$} \\
\hline & $\begin{array}{c}\text { First stage } \\
\text { Job Satisfaction }\end{array}$ & $\begin{array}{c}\text { Second stage } \\
\text { Subjective well-being }\end{array}$ & \\
\hline Job satisfaction & & $0.860 * * *$ & $0.302 * * *$ \\
\hline Age & $0.021 * * *$ & $-0.049 * * *$ & $-0.061 * * *$ \\
\hline $\mathrm{Age}^{2}$ & $0.001 * * *$ & $0.001 * * *$ & $0.001 * * *$ \\
\hline \multicolumn{4}{|l|}{ Gender } \\
\hline Male & Ref. & Ref. & Ref. \\
\hline Female & $0.061 * *$ & 0.024 & $0.076 * * *$ \\
\hline \multicolumn{4}{|l|}{ Income } \\
\hline $1^{\text {st }}$ quintile & Ref. & Ref. & Ref. \\
\hline $2^{\text {nd }}$ quintile & $0.456^{* * *}$ & $0.169 *$ & $0.434 * * *$ \\
\hline $3^{\text {rd }}$ quintile & $0.530 * * *$ & $0.400 * * *$ & $0.698 * * *$ \\
\hline $4^{\text {th }}$ quintile & $0.718 * * *$ & $0.518 * * *$ & $0.921 * * *$ \\
\hline $5^{\text {th }}$ quintile & $1.001 * * *$ & $0.545 * * *$ & $1.000 * * *$ \\
\hline \multicolumn{4}{|l|}{ Marital Status } \\
\hline Not in a union & Ref. & Ref. & Ref. \\
\hline Married & -0.082 & $0.142 * *$ & 0.085 \\
\hline Civil Union & 0.015 & -0.056 & -0.071 \\
\hline Separated & -0.07 & $-0.617 * * *$ & $-0.647 * * *$ \\
\hline Divorced & -0.069 & $-0.355 * * *$ & $-0.411 * * *$ \\
\hline Widowed & 0.025 & $-0.576^{* * *}$ & $-0.579 * * *$ \\
\hline \multicolumn{4}{|l|}{ Nationality } \\
\hline National & Ref. & Ref. & Ref. \\
\hline Foreigner & $-0.143 * * *$ & $0.111 * *$ & 0.022 \\
\hline \multicolumn{4}{|l|}{ Employment status } \\
\hline Fixed-term employee & Ref. & Ref. & Ref. \\
\hline Permanent employee & $0.079^{*}$ & -0.005 & 0.048 \\
\hline No contract & 0.042 & -0.037 & -0.026 \\
\hline Family business & $0.373 * *$ & -0.140 & 0.060 \\
\hline Self-employed & $0.500 * * *$ & $-0.170^{*}$ & 0.079 \\
\hline \multicolumn{4}{|l|}{ Education } \\
\hline Primary & Ref. & Ref. & Ref. \\
\hline Lower secondary & -0.104 & 0.100 & 0.038 \\
\hline Upper secondary & $-0.160 * *$ & 0.096 & 0.007 \\
\hline Tertiary & -0.081 & $0.149^{*}$ & 0.106 \\
\hline \multicolumn{4}{|l|}{ Welfare System } \\
\hline Eastern & Ref. & Ref. & Ref. \\
\hline Continental & $0.742 * * *$ & $0.612 * * *$ & $1.033 * * *$ \\
\hline
\end{tabular}




\begin{tabular}{lccc}
\hline Anglo-Saxon & $0.400^{* * *}$ & $0.665^{* * *}$ & $0.907^{* * *}$ \\
\hline Mediterranean & $0.324^{* * *}$ & $0.552^{* * *}$ & $0.748^{* * *}$ \\
\hline Nordic & $0.832^{* * *}$ & $1.044^{* * *}$ & $1.530^{* * *}$ \\
\hline Other & $0.271^{* * *}$ & $0.538^{* * *}$ & $0.716^{* * *}$ \\
\hline Working on weekends & & & \\
\hline Less than once a month & Ref. & & \\
\hline More than once a month & $-0.119^{* * *}$ & & \\
\hline $\begin{array}{l}\text { Working } \text { overtime on short } \\
\text { notice }\end{array}$ & & & \\
\hline Less than once a month & Ref. & \\
\hline More than once a month & $-0.141^{* * *}$ & & \\
\hline Observations & 18418 & & \\
\hline
\end{tabular}

Notes: *** significant at 0.01 level, $* * 0.05$ level, $* 0.10$ level.

Source: ESS 2010

The results were in line with the expectations with respect to the first stage regression. Both the instrumental variables were statistically significant at the $1 \%$ level: people that have to work on weekends or overtime on short notice were more likely not to be satisfied with their job. The effectiveness of the IV regression is due to the high correlation of the items with the endogenous variable: in the first stage the explanatory variables were altogether significant with an F-statistic of 49.18 (see Table 3 denoting a value that is excellent in order to support the relevance of the items according to Baum et al., 2003). In the second stage, job satisfaction was one of the main predictors of the individual's SWB with a positive and highly significant coefficient. The estimated coefficient resulting from the OLS estimation was also significant but much smaller and potentially affected by endogeneity.

Concerning the control variables, the results were the following: belonging to the highest quintile of income had a positive and major influence on SWB, with respect to the reference category, that is the lowest level of income. Furthermore, the results support a Ushaped relationship between age and SWB: the coefficient for age was negative and significant, whereas for the squared term it was positive and significant. Age did not significantly affect satisfaction at work. In contrast with the literature, in the present analysis the level of education in general did not have a statistically major influence on SWB. With regard to marital status, results were in part in line with this paper's expectations: on the one hand being separated, divorced (or civil union dissolved) and widowed (or civil partner died) all had a negative effect on the individual's SWB; on the other hand being legally married or in a legally registered civil union was not significant, with respect to the reference category of never having been married or in a registered civil union. None of these categories had a significant effect on the individual's job satisfaction.

Regarding the welfare system, the Nordic system was the best in terms of the average level of SWB while the Eastern system was the worst. Finally, the employment status, regarding the type of employment relationship and the contract duration, was not significant except for self-employed in the IV regression.

To further support the superiority of the IV method concerning the OLS regression, Sargan and Hausman's test was run. Results, which are reported in Table 3, are in favor of the IV method. 
Table 3. Instrumental variable estimation diagnostic

\begin{tabular}{lc}
\hline Validity of the instruments & \\
Sargan statistic (overidentification test of all instruments) & 0.353 \\
\hline $\begin{array}{l}\text { Relevance of the instruments } \\
\text { F statistic of first stage regression: }\end{array}$ & $49.18^{* * *}$ \\
\hline $\begin{array}{l}\text { Test of Endogeneity } \\
\text { Hausman statistic }\end{array}$ & $64.84 * * *$ \\
\hline
\end{tabular}

Notes: *** significant at 0.01 level, $* * 0.05$ level, $* 0.10$ level.

Source: ESS 2010

The Sargan statistic can be calculated for cases in which the model is "overidentified," that is when the number of items exceeds the number of endogenous variables. This test is implemented in order to judge whether the items are valid (i.e. they are exogenous and affect the dependent variable only indirectly) or not. Results supported accepting the null hypothesis that the instruments for job satisfaction are exogenous, even if Clarke and Matta (2018) observed that Sargan statistic is only a necessary and not sufficient condition for supporting validity. The Hausman test is, instead, an indirect test for the endogeneity of the instrumented variable. Results were against the null hypothesis of no systematic differences in the coefficients; this suggests that using the IV estimator produces consistent and more efficient estimates for the impact of job satisfaction on SWB.

Table 4. Nevo and Rosen (2012)'s Imperfect IV bounds for the coefficient of Subjective wellbeing - 2SLS estimations.

\begin{tabular}{ll}
\hline Lower Bound (Confidence Interval) & 0.290 \\
\hline Lower Bound (Estimator) & 0.302 \\
\hline Upper Bound (Estimator) & 0.731 \\
\hline Upper Bound (Confidence Interval) & 1.136 \\
\hline
\end{tabular}

Notes: Confidence Interval at 0.95 level

Source: ESS 2010

An additional robustness check has been provided in Table 4, showing bounds for both point and interval estimations of the coefficient of Subjective well-being (second stage estimations), according to Nevo and Rosen (2012).

In the 2SLS estimations the coefficient of Job Satisfaction is larger than what has been observed in OLS regression. This result combined with that from the Hausman test denotes that OLS regression underestimates the effect of Job Satisfaction on SWB. This happens when the correlation between the error term and the endogenous variable in the main equation is negative. Hence, we have estimated Nevo and Rosen (2012)'s bounds for estimates of the effect of SWB, assuming a negative correlation with the error and overidentification (Clarke and Matta, 2018).

As we can see in Table 4, when we relax the hypothesis of validity of both the instruments (already excluded in Table 3), the estimation of the coefficient of JS changes. The range of variation for the point estimate is limited between 0.302 and 0.731 , underlining the robustness of estimates from Table 2; after taking into account the margin of error occurring in the case of simple random samples, the confidence interval at $95 \%$ level suggests a range for beta between 0.290 and 1.136, confirming the significance of the effect of Job Satisfaction in explaining variation of overall SWB. 


\section{Concluding remarks}

The ongoing development in the research on subjective well-being recently involved the scientific debate. Past evidence has shown that certain life domains are crucial in influencing the subjective well-being of individuals, and, in particular, its main dimensions, which are happiness and life satisfaction. This paper underlines the importance of the work domain, embracing the so-called part-whole theory, according to which job satisfaction is one of the determinants of SWB. In details, we tested the hypothesis that changes in job satisfaction affect the overall subjective well-being. The relationship between these two dimensions is ambiguous; thus, a simple positive correlation does not mean that job satisfaction increases happiness and life satisfaction. In order to identify whether a variation in job conditions increases or decreases SWB, we implemented an instrumental variable approach: we firstly used variables such as the frequency of working at weekends and overtime with a short notice to predict job satisfaction of individuals and subsequently used these fitted values to establish whether job satisfaction has an impact on subjective well-being. Those two variables which are selected as instruments would be both considered to be highly correlated with job satisfaction, but not directly with overall subjective well-being.

Moreover, these instruments are supposed to be linked with the frequency by which a worker participates in weekends or the overtime working. Two conditions must be satisfied to produce unbiased estimates for the effect of JS on SWB: 1) relevance and 2) validity. The Sargan statistic supports the assumption that these potential instruments are exogenous and uncorrelated with the overall subjective well-being in the first equation through the error term. Furthermore, instruments are relevant; thus, they help to explain changes in job satisfaction satisfactorily. After having implemented an instrumental variable regression and replaced the original value with the fitted job satisfaction, we discover that the relationship still is significantly correlated with subjective well-being, proving that job satisfaction has a causal effect on subjective well-being. The novelty of our analysis is two-folded: 1) on the one hand we reinforce the instrumental variable approach from Sironi (2019) by implementing a new strategy in evaluating the robustness of estimates, introducing bounds for IV estimates (Nevo and Rosen, 2012). In the light of new confidence interval for the effect of JS on SWB, we can assure that the significance is also confirmed after having relaxed the hypothesis of validity; 2) we confirm an impact of JS improvement on SWB, also by enlarging the analysis to a metric indicator of SWB.

\section{References}

Asatiani, M., \& Verulava, T. (2017). Georgian welfare state: Preliminary study based on esping-andersen's typology. Economics and Sociology, 10(4), 21-28.

Bakotić, D. (2016). Relationship between job satisfaction and organisational performance. Economic research-Ekonomska istraživanja, 29(1), 118-130.

Baum, C.F., Schaffer, M.E., \& Stillman, S. (2003). Instrumental variables and GMM: Estimation and testing. Stata Journal, 3(1), 1-31.

Baptiste, N. R. (2008). Tightening the link between employee well-being at work and performance: A new dimension for HRM Management Decision, 46, 284-309.

Bilan, Y., Simionescu, M., Vojtovič, S., \& Zapototskyi, S. (2019). The impact of religiosity on individual perception of well-being and living standards: A cross-cultural study on selected developing economies. Journal of Population and Social Studies [JPSS], 27(4), 347-358. 
Blanchflower, D.G., \& Oswald, A.J. (2007). Is well-being U-shaped over the life cycle?, NBER Working Paper No. 12935. Cambridge, Mass: National Bureau of Economic Research.

Boamah, S. A., Laschinger, H. K. S., Wong, C., \& Clarke, S. (2018). Effect of transformational leadership on job satisfaction and patient safety outcomes. Nursing outlook, 66(2), 180189

Bowling, N.A., Eschleman, K.J., \& Wang, Q. (2010). A meta-analytic examination of the relationship between job satisfaction and subjective well-being. Journal of Occupational and Organizational Psychology, 83(4), 915-934.

Bratu, M. L., \& Cioca, L. I. (2018). Adaptation of managerial style to the personality of engineers, in order to increase performance in the workplace. Polish Journal of Management Studies, 17(1), 67-77.

Bryson, A., Gomez, R., Kretschmer, T., \& Willman, P. (2007). the diffusion of workplace voice and high-commitment human resource management practices in Britain, 1984-1998, Industrial and Corporate Change, 16(3), 395-426.

Bryson, A., Forth, J., \& Stokes, L. (2017), Does employees' subjective well-being affect workplace performance?, Human Relations, 70(8), 1017-1037.

Bruni, L. (2010). The happiness of sociality. Economics and eudaimonia: A necessary encounter, Rationality and Society, 22(4), 383-406.

Bruni, L., \& Porta, P.L. (2007). Handbook on the Economics of Happiness. Edward Elgar, Cheltenham, UK.

Clark, A.E., \& Oswald, A.J. (1994). Unhappiness and unemployment. Economic Journal, 104 (424), 648-659.

Clarke, D., \& Matta, B. (2018). Practical considerations for questionable IVs. The Stata Journal, 18(3), 663-691.

Diener, E. (1984). Subjective well-being. Psychological Bulletin, 95, 542-575.

Diener, E. (2000). Subjective well-being: The science of happiness and a proposal for a national index. American Psychologist, 55(1), 34-43.

Diener, E., Lucas, R.E., Oishi, S., \& Suh, E.M. (2002), Looking up and looking down: weighting good and bad information in life satisfaction judgements. Personality and Social Psychology Bulletin, 28, 437-445.

Diener, E., Sandvik, E., Seidlitz, L., \& Diener, M. (1993), The relationship between income and subjective well-being: relative or absolute?, Social Indicators Research, 28(3), 195223.

D'Silva, J. L., \& Samah, A. A. (2018). Holistic well-being of Japanese retirees in Malaysia. Journal of International Studies, 11(3), 95-103. doi:10.14254/2071-8330.2018/11-3/8

Dolbier, C. L., Webster, J. A., McCalister, K. T., Mallon, M. W., \& Steinhardt, M. A. (2005). Reliability and validity of a single-item measure of job satisfaction. American Journal of Health Promotion, 19(3), 194-198.

Esping-Andersen, G. (1990), Three Worlds of Welfare Capitalism, Polity Press, Cambridge.

Foote, D. A. and Li-Ping Tang, T. (2008). Job satisfaction and organizational citizenship behavior (OCB) does team commitment make a difference in self-directed teams? Management Decision, 46, 933-947.

Frey, B. and Stutzer, A. (2002). The Economics of Happiness. World Economics, 3(1), 25-41.

Frone, M.R., Russell, M., \& Cooper, M.L. (1994). Relationship between job and family satisfaction: causal or non-causal covariation?. Journal of Management, 20(3), 565-579.

Goyal, S., B.S. Sergi, \& A. Kapoor (2014). Understanding the key characteristics of an embedded business model for the base of the pyramid markets. Economics \& Sociology $7(4), 26-40$. 
Hameed, F., Ahmed-Baig, I., \& Cacheiro-González. M.L. (2018). Job satisfaction of teachers from public and private sector universities in Lahore, Pakistan: A comparative study. Economics and Sociology, 11(4), 230-245. doi:10.14254/2071-789X.2018/11-4/15

Headey, B., Veenhoven, R. and Wearing, A. (1991). Top-down versus bottom-up theories of subjective well-being. Social Indicators Research, 24, 81-100.

Herzberg, F.I. (1976). Motivation-Hygiene Profiles. Organizational Dynamics, 3(2), 18-29.

Huppert, F. A., \& So, T. T. (2013). Flourishing across Europe: Application of a new conceptual framework for defining well-being. Social indicators research, 110(3), 837-861.

Igalens, J., \& Roussel, P. (1999). A study of the relationships between compensation package, work motivation and job satisfaction. Journal of Organizational Behavior, 20, 10031025 .

Judge, T.A., \& Hulin, C.L. (1993). Job satisfaction as a reflection of disposition: A multiple source causal analysis. Organizational Behavior and Human Decision Processes, 56, $388-421$.

Judge, T.A., \& Locke, E.A. (1993). Effect of dysfunctional thought processes on subjective well-being and job satisfaction. Journal of Applied Psychology, 78, 475-490.

Judge, T.A., Locke, E.A., Durham, C.C., \& Kluger, A.N. (1998). Dispositional effects on job and life satisfaction: The role of core evaluations. Journal of Applied Psychology, 83, $17-$ 34.

Judge, T.A., \& Watanabe, S. (1993). Another look at the job satisfaction-life satisfaction relationship. Journal of Applied Psychology, 78, 939-948.

Kaasa, A. (2016). Social capital, institutional quality and productivity: evidence from European regions. Economics \& Sociology, 9(4), 11-26.

Lambert, E.G., Qureshi, H., Frank, J. et al. (2018). J Police Crim Psych, 33, 85. https://doi.org/10.1007/s11896-017-9236-y

Lazányi, K., \& Bilan, Y. (2017). Generetion Z on the labour market: do they trust others within their workplace?. Polish Journal of Management Studies, 16(1), 78-93.

Luthans, F., Avolio, B. J., Avey, J. B., \& Norman, S. M. (2007). Positive psychological capital: Measurement and relationship with performance and satisfaction. Personnel psychology, 60(3), 541-572.

Locke, E.A. (1976). The nature and causes of job satisfaction. In M. D. Dunnette (Ed.), Handbook of Industrial and Organizational Psychology. Rand McNally, Chicago, IL, 1297-1343.

Lucas, R.E., Clark, A.E., Georgellis, Y., \& Diener, E. (2003). Reexamining adaptation and the set-point model of happiness: Reactions to changes in marital status. Journal of Personality and Social Psychology, 84, 527-539.

Medvedev, O. N., \& Landhuis, C. E. (2018). Exploring constructs of well-being, happiness and quality of life. PeerJ, 6, e4903.

Near, J.P., Rice, R.W., \& Hunt, R.G. (1978). Work and extra-work correlates of life and job satisfaction. Academy of Management Journal, 21, 248-264.

Nevo, A., \& Rosen, A. M. (2012). Identification with imperfect instruments. Review of Economics and Statistics, 94(3), 659-671.

Poggi, A. (2010). Job satisfaction, working conditions and aspirations. Journal of Economic Psychology, 31(6), 936-949.

Rice, R.W., Near, J.P., \& Hunt, R.G. (1980). The job-satisfaction/life-satisfaction relationship: A review of empirical research. Basic and Applied Social Psychology, 1, 37-64.

Šabić-Lipovača, A., Strielkowski, W., \& Bilan, Y. (2016). Intertemporal substitution and labour supply of Bosnian SME's. Amfiteatru Economic Journal, 18(43), 634-653. 
Saridakis, G., Muñoz-Torres, R., \& Tracey, P. (2009). The endogeneity bias in the relationship between employee commitment and job satisfaction, Cambridge Judge Business School, Working Paper Series, 2009(3), 1-15.

Schmalbach, J. C. V., \& Avila, F. J. M. (2018). Structural Equation Models Applied for Evaluating Service Quality and Satisfaction in the Healthcare System of Cartagena de Indias DT y C.(Colombia). Economics \& Sociology, 11(2), 200-215.

Sironi, E. (2019). Job satisfaction as a determinant of employees' optimal well-being in an instrumental variable approach. Quality \& Quantity, 53(4), 1721-1742.

Soede, A.J., Vrooman J.C., Ferraresi P.M., \& Segre G. (2004). Unequal Welfare States, SCP, The Hague.

Stefanovska-Petkovska, M., \& Bojadziev, M. (2017). Cash or Compliment? Older employees preference of financial versus non-financial incentives. Montenegrin Journal of Economics, 13(1), 63-71.

Stefanovska-Petkovska, M., Petrovska, I., Bojadziev, M., Schaeffer, I., \& TomovskaMisoska, A. (2019). The effects of organizational culture and dimensions on job satisfaction and work-life balance. Montenegrin Journal of Economics, 15(1), 99-112.

Suh, E.M., Diener, E., \& Fujita, F. (1996). Events and subjective well-being: only recent events matter. Journal of Personality and Social Psychology, 70, 1091-1102.

Vdovtsova, S. (2008). Motivation mechanisms of youth behavior on Ukrainian labour market. Economics \& Sociology, 1(1), 104-109

Yahyagil, M.Y. (2015). Values, feelings, job satisfaction and well-being: The Turkish case, Management Decision, 53(10), 2268-2286. 